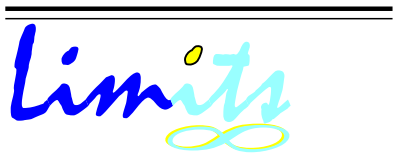

J. Math. and Its Appl.

ISSN : 1829-605X

Vol. 2, No. 2, Nov 2005, 103-115

\title{
Penentuan Bifurkasi Hopf Pada Predator Prey
}

\author{
Dian Savitri \\ Jurusan Teknik Sipil, Fakultas Teknik \\ Universitas Negeri Surabaya \\ d3_savitri@yahoo.com
}

\begin{abstract}
Abstrak
Dalam makalah ini, dikaji dinamika dalam sistem dinamik pada permasalahan predator prey yaitu tentang penentuan bifurkasi Hopf dengan membandingkan dua metode. Metode yang digunakan untuk menentukan jenis bifurkasi Hopf adalah kriteria divergensi dan teori penyelesaian bentuk normal. Dengan menentukan kestabilan dari titik setimbang bifurkasi akan diketahui jenis bifurkasinya, jika titik setimbang stabil maka merupakan bifurkasi Hopf superkritikal, jika titik setimbang tidak stabil disebut bifurkasi Hopf subkritikal.

Pada penyelesaian bentuk normal sistem atau model harus ditransformasikan sehingga diperoleh bentuk normal bifurkasi Hopf dengan terlebih dahulu mentranslasikan titik setimbang ke titik $(0,0)$, kemudian sistem diubah ke bentuk baku/standar melalui diagonalisasi matriks dan menentukan titik bifurkasi Hopf serta menentukan tanda (positif atau negatif) dari index stabilitas. Pada kriteria divergensi terlebih dahulu dibentuk sistem yang baru dan diselidiki sifat definit dari bentuk kuadrat di suatu sekitaran titik setimbang oleh karena itu perlu dicari koefisien dari fungsi kuadrat. Kemudian dianalisis untuk menentukan divergensinya, divergensi $\phi$ positif jika $\phi_{x x}$ positif dan divergensi $\phi_{x x}$ negatif jika $\phi_{x x}$ negatif. Pada paper ini akan dibandingkan dua metode yaitu penyelesaian bentuk normal dan kriteria divergensi untuk menentukan jenis bifurkasi Hopf yang diterapkan pada system predator prey. Dengan demikian dapat diketahui metode mana yang lebih
\end{abstract}


sederhana dan lebih mudah dalam langkah penyelesaian, sehingga dapat dijadikan sebagai metode alternatif dalam menentukan bifurkasi Hopf. Kemudian dilakukan analisis titik setimbang pada system predator prey, didapat tiga titik setimbang dan pada salah satu titik setimbang tersebut merupakan bifurkasi Hopf superkritikal.

Kata kunci: kriteria divergensi, penyelesaian bentuk normal, bifurkasi Hopf

\section{Pendahuluan}

Pada sistem dinamik salah satu yang sering dikaji adalah tentang orbit periodik. Dalam makalah ini, untuk menentukan jenis orbit periodik yaitu bifurkasi Hopf superkritikal dan bifurkasi Hopf subkritikal pada permasalahan predator prey, digunakan dua metode dalam penyelesaiannya. Metode yang digunakan adalah penyelesaian bentuk normal dan kriteria divergensi. Dengan membandingkan dua metode tersebut diharapkan diperoleh metode mana yang langkah penyelesaiannya lebih mudah dan lebih sederhana. Pada penyelesaian bentuk normal, sistem atau model harus ditransformasikan terlebih dahulu sehingga diperoleh bentuk normal bifurkasi Hopf. Langkah pertama adalah mentranslasikan titik setimbang ke titik $(0,0)$, kemudian sistem diubah ke bentuk baku/ standar melalui diagonalisasi matriks dan menentukan titik bifurkasi Hopf serta menentukan tanda (positif atau negatif) dari index stabilitas. . Pada kriteria divergensi terlebih dahulu dibentuk sistem yang baru dan diselidiki sifat definit dari bentuk kuadrat di suatu sekitaran titik setimbang oleh karena itu perlu dicari koefisien dari fungsi kuadrat $a(x, y)$. Kemudian dianalisis untuk menentukan divergensinya, divergensi $\phi$ positif jika $\phi_{x x}$ positif dan divergensi $\phi$ negatif jika $\phi_{x x}$ negatif.

\section{Sistem Predator Prey}

Diberikan suatu sistem predator prey

$$
\begin{aligned}
& \dot{x}=x(1-x)-\frac{2 x y}{1+2 x} \\
& \dot{y}=y\left(\frac{2 x}{1+2 x}-\mu\right)
\end{aligned}
$$

dimana

$x=$ banyaknya populasi dari prey

$y=$ banyaknya populasi predator

$\mu=$ parameter (diasumsikan positif) 
Persamaan 1 menjelaskan keadaan pada suatu lingkungan hidup terdapat 2 spesies hewan dengan populasi $x$ menyatakan spesies prey dan populasi $y$ menyatakan spesies predator. Laju pertumbuhan Prey diketahui sebesar satu dan Predator $\frac{2 x}{1+2 x}$. Serta laju kematian predator adalah $\mu$. Kemudian akan dianalisa kestabilan titik setimbang. Misal $(\bar{x}, \bar{y})$ titik setimbang sistem (1), sehingga

$$
f(\bar{x}, \bar{y})=0 \quad g(\bar{x}, \bar{y})=0
$$

maka sistem (1) mempunyai tiga titik setimbang:

$$
T_{0}=(0,0), \quad T_{1}=(0,0), \quad \text { dan } \quad T_{c}=\left(\frac{\mu}{2(1-\mu)}, \frac{2-3 \mu}{4(1-\mu)^{2}}\right)
$$

Untuk mendapatkan kestabilan dari masing-masing titik setimbang, terlebih dahulu dilakukan pelinieran. Kestabilan setiap titik setimbang ditentukan dengan mencari nilai eigen. Matriks Jacobi sistem (1) di titik setimbang $(\bar{x}, \bar{y})$ adalah

$$
J=\left(\begin{array}{cc}
1-2 x-\frac{2 y}{(1+2 x)^{2}} & -\frac{2 x}{1+2 x} \\
\frac{2 y}{(1+2 x)^{2}} & \frac{2 x}{(1+2 x)-\mu}
\end{array}\right)
$$

\subsection{Analisa Kestabilan Titik Setimbang}

Kestabilan Lokal Titik Setimbang $T_{0}$

Dari titik setimbang $T_{0}=(0,0)$ maka matriks Jacobi di titik setimbang $(0,0)$ adalah:

$$
J_{0}=\left(\begin{array}{ll}
1 & 0 \\
0 & \mu
\end{array}\right)
$$

Nilai eigen didapat dari $\left|J_{0}-\lambda I\right|=0$, yaitu

$$
J_{0}=\left|\begin{array}{cc}
1-\lambda & 0 \\
0 & -\mu-\lambda
\end{array}\right|=(1-\lambda)(-\mu-\lambda)=0
$$

dengan akar-akar karakteristik atau nilai eigen

$$
\lambda_{1}=1, \quad \lambda_{2}=-\mu
$$

Eigen vektor untuk $\lambda_{1}=1$, maka

$$
\left(\begin{array}{cc}
0 & 0 \\
0 & -\mu-\lambda
\end{array}\right)\left(\begin{array}{l}
\xi_{1} \\
\xi_{2}
\end{array}\right)=\left(\begin{array}{l}
0 \\
0
\end{array}\right)
$$

sehingga

$$
\xi_{1}=\text { sebarang } \quad \text { dan } \quad \xi_{2}=0
$$

oleh karena itu $E^{u}=\left(\begin{array}{l}0 \\ 1\end{array}\right)$ sub ruang yang tidak stabil. 
Sedangkan eigen vektor untuk $\lambda_{2}=-\mu$, maka

$$
\left(\begin{array}{cc}
1-\mu & 0 \\
0 & 0
\end{array}\right)\left(\begin{array}{l}
\xi_{1} \\
\xi_{2}
\end{array}\right)=\left(\begin{array}{l}
0 \\
0
\end{array}\right)
$$

sehingga

$$
\xi_{1}=0 \quad \text { dan } \quad \xi_{2}=\text { sebarang }
$$

oleh karena itu $E^{s}=\left(\begin{array}{l}0 \\ 1\end{array}\right)$ sub ruang yang stabil.

Pada titik setimbang $(0,0)$ nilai eigennya satu positif dan satu negative. Dengan demikian titik setimbang $(0,0)$ bersifat tidak stabil bertipe titik sadel (saddle point) dengan manifold stabil $E^{s}=\{(x, y): x=0, y \geq 0\}$ dan manifold tidak stabil $E^{u}=\{(x, y): y=0, x \geq 0\}$. Dalam keadaan ini berarti populasi predator punah dan populasi prey dapat bertahan hidup.

Kestabilan Lokal Titik Setimbang $T_{1}$

Untuk titik $T_{1}=(1,0)$, matriks Jacobi menjadi:

$$
J_{1}=\left(\begin{array}{cc}
-1 & 0 \\
0 & \frac{2}{3}-\mu
\end{array}\right)
$$

Nilai eigen di titik $T_{1}=(1,0)$ diperoleh dari

$$
\left|\begin{array}{cc}
-1-\lambda & 0 \\
0 & \frac{2}{3}-\mu-\lambda
\end{array}\right|=(-1-\lambda)\left(\frac{2}{3}-\mu-\lambda\right)=0
$$

dengan akar-akar karakteristik atau nilai eigen

$$
\lambda_{1}=-1, \quad \lambda_{2}=\frac{2}{3}-\mu
$$

Karena $\lambda_{1}=-1<0$, jika $\lambda_{1}<0, \lambda_{2}<0$ maka titik setimbang $(1,0)$ bersifat stabil jika dan hanya jika $\lambda_{2}=\frac{2}{3}-\mu<0$. Dengan demikian titik setimbang $T_{1}=(1,0)$ stabil asimtotis lokal yang berarti pertumbuhan prey mencapai carrying capacity (populasi prey mencapai pertumbuhan maksimum) dan predator musnah. Dalam keadaan ini kemungkinan yang terjadi pada awal system tidak ada populasi predator atau laju kematian populasi predator sangat tinggi.

\section{Kestabilan Lokal Titik Setimbang $T_{c}$}

Titik setimbang ke tiga adalah $T_{c}=\left(\frac{\mu}{2(1-\mu}-\frac{2-3 \mu}{4(1-\mu)^{2}}\right)$. Untuk menentukan sifat kestabilan dari sistem (1) maka langkah yang harus dilakukan adalah mencari nilai eigen dari matriks Jacobi di titik setimbang $T_{c}$.

Matriks Jacobi di titik setimbang $T_{c}=\left(\frac{\mu}{2(1-\mu}-\frac{2-3 \mu}{4(1-\mu)^{2}}\right)$ 


$$
J=\left(\begin{array}{cc}
1-\frac{\mu}{1-\mu}-\frac{2-3 \mu}{2} & \mu \\
\frac{2-3 \mu}{2(1-\mu)^{2}} & 0
\end{array}\right)
$$

Pada titik $T_{c}$ nilai eigen dari matriks Jacobi dapat diperoleh dari $|\lambda I-J|=0$

$$
J=\left|\begin{array}{cc}
\lambda-\left(1-\frac{\mu}{1-\mu}-\frac{2-3 \mu}{2}\right) & \mu \\
-\frac{2-3 \mu}{2(1-\mu)^{2}} & \lambda
\end{array}\right|=0
$$

atau

$$
(\lambda)^{2}-\left(\frac{\mu(1-3 \mu)}{2(1-\mu)}\right) \lambda+\left(\frac{2-3 \mu}{2(1-\mu)^{2}}\right) \mu=0
$$

maka akar-akar karakteristik adalah

$$
\lambda_{1,2}=\frac{\left(\frac{\mu(1-3 \mu)}{2(1-\mu)}\right) \pm \sqrt{\left(\frac{\mu(1-3 \mu)}{2(1-\mu)}\right)^{2}-4\left(\frac{2-3 \mu}{2(1-\mu)^{2}}\right) \mu}}{2}
$$

Saat $\operatorname{tr}(J)=0$ maka $\frac{\mu(1-3 \mu)}{2(1-\mu)}=0$, didapat $1-3 \mu=0, \mu=\frac{1}{3}$ dengan nilai eigen yaitu $\lambda_{1,2}=\frac{1}{2} \pm \sqrt{\frac{3}{4}} i= \pm i \sqrt{\frac{3}{8}}$. Saat $\mu=\frac{1}{3}$ maka titik setimbang menjadi $T_{c}=\left(\frac{1}{4}, \frac{9}{16}\right)$.

Karena nilai eigen imajiner $\lambda_{1,2}= \pm i \sqrt{\frac{3}{8}}$ bagian real nol, berarti titik setimbang $T_{c}=\left(\frac{1}{4}, \frac{9}{16}\right)$ bersifat center. Dalam keadaan ini terdapat populasi prey dan juga populasi predator yang hidup secara berdampingan bersama-sama dalam satu lingkungan.

Pada titik setimbang $T_{c}=\left(\frac{1}{4}, \frac{9}{16}\right)$ nilai eigen imajiner murni, sehingga ada kemungkinan terjadi bifurkasi Hopf. Untuk itu perlu analisa bifurkasi untuk menentukan jenis bifurkasi Hopf (bifurkasi Hopf superkritikal atau bifurkasi Hopf subkritikal).

\section{Penentuan Bifurkasi Hopf}

Ada dua metode untuk menentukan jenis bifurkasi Hopf yang akan dibahas dalam paper ini, yaitu metode penyelesaian bentuk normal dan kriteria divergensi.

\subsection{Penentuan Bifurkasi Hopf Dengan Bentuk Normal}

Langkah-langkah untuk menentukan Bifurkasi Hopf

1. Menentukan syarat terjadi bifurkasi Hopf Syarat terjadinya bifurkasi Hopf adalah 
- $\operatorname{Re} \lambda(\mu)=\alpha_{\mu}=0$

- $\operatorname{Im} \lambda(\mu)=\omega \neq 0$

- Syarat transversal

$$
d=\left.\frac{d \alpha_{\mu}}{d \mu}\right|_{\mu=\frac{1}{3}}=\frac{3}{4}-\left.\frac{1}{2(1-\mu)^{2}}\right|_{\mu=\frac{1}{3}}=-\frac{3}{8}<0
$$

Untuk mengetahui jenis bifurkasi Hopf apakah bifurkasi Hopf subkritikal atau superkritikal, maka langkah berikutnya adalah mencari bentuk normal bifurkasi Hopf, kemudian menentukan tanda pada index stabilitas, apakah positif atau negatif.

2. Mencari bentuk normal bifurkasi Hopf

Translasi titik setimbang $T_{c}=\left(\frac{1}{4}, \frac{9}{16}\right)$ ke $(0,0)$.

$$
p=x-\frac{1}{4} \quad q=y-\frac{9}{16}
$$

maka diperoleh $\dot{p}=\dot{x}$ dan $\dot{q}=\dot{y}$ dimana $x=p+\frac{1}{4}$ dan $y=q+\frac{9}{16}$ sehingga diperoleh $\dot{p}=-\frac{1}{2} q-2 q-2 p^{3}-\frac{1}{2} p^{2}-2 p q+\frac{1}{4}$ dan $\dot{q}=\frac{3}{4} p+\frac{4}{3} p q$ dapat ditulis dalam bentuk

$$
\left(\begin{array}{c}
\dot{p} \\
\dot{q}
\end{array}\right)=\left(\begin{array}{cc}
0 & -\frac{1}{2} \\
\frac{3}{4} & 0
\end{array}\right)\left(\begin{array}{c}
p \\
q
\end{array}\right)+\left(\begin{array}{c}
-2 q-2 p^{3}-\frac{1}{2} p^{2}-2 p q+\frac{1}{4} \\
\frac{4}{3} p q
\end{array}\right)
$$

Eigen vektor yang bersesuaian dengan $\lambda=i \sqrt{\frac{3}{8}}$ adalah dan $\left(\begin{array}{c}\sqrt{\frac{3}{8}} \\ 0\end{array}\right)$ dan $\left(\begin{array}{c}0 \\ -\frac{3}{4}\end{array}\right)$ sehingga diperoleh matriks transformasi

$$
T=\left(\begin{array}{cc}
\sqrt{\frac{3}{8}} & 0 \\
0 & -\frac{3}{4}
\end{array}\right)
$$

3. Gunakan Transformasi untuk menentukan Bentuk Kanonik Medan Vector Dengan menggunakan matriks transformasi $T$ variabel $p$ dan $q$ ditransformasikan menjadi vektor $u$ dan $v$, yaitu

$$
\left(\begin{array}{c}
p \\
q
\end{array}\right)=T\left(\begin{array}{l}
u \\
v
\end{array}\right)=\left(\begin{array}{cc}
\sqrt{\frac{3}{8}} & 0 \\
0 & -\frac{3}{4}
\end{array}\right)\left(\begin{array}{l}
u \\
v
\end{array}\right)
$$

didapat $p=\sqrt{\frac{3}{8}} u$ dan $q=-\frac{4}{3} v$ sehingga dengan matriks $T$ dan $T^{-1}$ didapat

$$
T\left(\begin{array}{c}
\dot{u} \\
\dot{v}
\end{array}\right)=\left(\begin{array}{cc}
0 & -\frac{1}{2} \\
\frac{3}{4} & 0
\end{array}\right) T\left(\begin{array}{c}
u \\
v
\end{array}\right)+\left(\begin{array}{c}
-\frac{3}{4} \sqrt{\frac{3}{8}} u^{3}-\frac{3}{16} u^{2}+\frac{3}{2} \sqrt{\frac{3}{8}} u v+\frac{1}{4} \\
-\sqrt{\frac{3}{8}} u v
\end{array}\right)
$$


atau

$$
\left(\begin{array}{c}
\dot{u} \\
\dot{v}
\end{array}\right)=\left(\begin{array}{cc}
0 & -\sqrt{\frac{3}{8}} \\
\sqrt{\frac{3}{8}} & 0
\end{array}\right)\left(\begin{array}{l}
u \\
v
\end{array}\right)+\left(\begin{array}{c}
-\frac{3}{4} u^{3}-\frac{1}{2} \sqrt{\frac{3}{8}} u^{2}+\frac{3}{2} u v \frac{2}{3} \sqrt{\frac{3}{8}} \\
\frac{4}{3} \sqrt{\frac{3}{8}} u v
\end{array}\right)
$$

Dalam hal ini dan

$$
\begin{aligned}
f(u, v) & =-\frac{3}{4} u^{3}-\frac{1}{2} \sqrt{\frac{3}{8}} u^{2}+\frac{3}{2} u v \frac{2}{3} \sqrt{\frac{3}{8}} \\
g(u, v) & =\frac{4}{3} \sqrt{\frac{3}{8}} u v
\end{aligned}
$$

merupakan bentuk normal form dari sistem (1)

4. Menentukan Index Stabilitas

Indeks kestabilan ditentukan dengan rumus

$$
\begin{aligned}
a & =\frac{1}{16}\left\{f_{u u u}+f_{u u v}+g_{u u v}+g_{v v v}\right\}+ \\
& =\frac{1}{16 \omega}\left\{f_{u v}\left(f_{u u}+f_{v v}\right)-g_{u v}\left(g_{u u}+g_{v v}\right)-f_{u u} g_{u u}+f_{v v} g_{v v}\right\}
\end{aligned}
$$

Sehingga diperoleh

$$
a=-0.375<0
$$

Karena maka terjadi bifurkasi Hopf superkritikal dengan orbit periodik stabil. Dengan demikian pada sistem predator prey penyelesaian dengan metode bentuk normal didapat jenis bifurkasi Hopf superkritikal.

\subsection{Penentuan Bifurkasi Hopf dengan Kriteria Divergensi}

\subsubsection{Kriteria Divergensi}

Misal diberikan sistem dinamik

$$
\dot{x}=f(x, y) \quad \dot{y}=g(x, y)
$$

diasumsikan bahwa $(0,0)$ adalah pusat (center), artinya medan vektor dengan titik setimbang $(0,0)$ berupa center. Titik setimbang $(0,0)$ mempunyai nilai eigen imajiner murni $\lambda(\mu)=\alpha(\mu) \pm i \omega(\mu)$. Bifurkasi Hopf terjadi pada saat nilai parameter $\mu=0$ dan $\omega(\mu) \neq 0$.

Jika divergensi dari medan vektor $(7)$ di titik setimbang $(0,0)$ bertanda negatif, maka titik setimbang $(0,0)$ merupakan spiral yang stabil sehingga dengan adanya center di sekitar titik $(0,0)$ berakibat terjadinya limit cycle stabil (bifurkasi Hopf 
superkritikal). Jika divergensi dari medan vektor (7) di titik setimbang $(0,0)$ bertanda positif, maka titik setimbang $(0,0)$ merupakan spiral yang tidak stabil sehingga dengan adanya center di sekitar titik $(0,0)$ berakibat terjadinya limit cycle tidak stabil (bifurkasi Hopf subkritikal). Metode untuk menentukan jenis bifurkasi Hopf seperti itu disebut dengan kriteria divergensi [5].

Dari asumsi sistem (7) bahwa $(0,0)$ merupakan titik setimbang center, yaitu pada titik tersebut berlaku

$$
f(0,0)=0, \quad g(0,0)=0, \quad f_{x}(0,0)+g_{y}(0,0)=0
$$

dan

$$
f_{x}(0,0) \cdot g_{y}(0,0)-f_{y}(0,0) \cdot g_{x}(0,0)>0
$$

berakibat

$$
\alpha_{1}=i \omega \quad \text { atau } \quad \alpha_{2}=-i \omega
$$

Karena $\operatorname{Re}\left(\alpha_{1}\right)=0$ dan $\operatorname{Re}\left(\alpha_{2}\right)=0$ maka kestabilan dari titik setimbang tidak dapat ditentukan, oleh karena itu perlu analisa bifurkasi dari titik setimbang $(0,0)$. Karena $(0,0)$ merupakan titik setimbang center yang ditunjukkan dengan adanya beberapa orbit periodik yang mengelilingi titik $(0,0)$, maka langkah selanjutnya menentukan jenis bifurkasi Hopf dengan metode khusus yang disebut kriteria divergensi.

\subsubsection{Penentuan Bifurkasi Hopf}

Pada bagian ini akan dicari koefisien dari $a(x, y)$ dengan bentuk:

$$
a(x, y)=1+a_{x}(0,0) x+a_{y}(0,0) y+\frac{1}{2}\left(a_{x x}(0,0) x^{2}+2 a_{x y}(0,0) x y+a_{y y}(0,0) y^{2}\right)
$$

Misal $\phi(x, y)$ adalah divergensi dari $(a f, a g)$, maka

$$
\begin{aligned}
\phi(x, y) & =\nabla \cdot(a(x, y) f(x, y), a(x, y) g(x, y)) \\
& =\nabla \cdot(a(x, y) f(x, y))+\nabla \cdot(a(x, y) g(x, y))
\end{aligned}
$$

sehingga didapat

$$
\phi(x, y)=a(x, y)\left(f_{x}(x, y)+g_{y}(x, y)\right)+a_{x}(x, y) f(x, y)+a_{y}(x, y) g(x, y)
$$

dengan syarat $\phi(x, y)$ definit positif. Selanjutnya digunakan Deret Taylor disekitar $(0,0)$ untuk fungsi $\phi(x, y)$ :

$$
\begin{aligned}
\phi(x, y)= & \phi(0,0)+\phi_{x}(0,0) x+\phi_{y}(0,0) y \\
& +\frac{1}{2}\left(\phi_{x x}(0,0) x^{2}+2 \phi_{x y}(0,0) x y+\phi_{y y}(0,0) y^{2}\right)+\cdots
\end{aligned}
$$


Dari asumsi sistem $(7)$ bahwa $(0,0)$ merupakan titik setimbang center, titik tersebut berlaku

$$
f(0,0)=g(0,0)=0, \quad f_{x}(0,0)+g_{y}(0,0)=0
$$

dan

$$
f_{x}(0,0) \cdot g_{y}(0,0)-f_{y}(0,0) \cdot g_{x}(0,0)>0
$$

sehingga didapat turunan pertama dari :

$$
\begin{aligned}
\phi_{x}(0,0) & =f_{x x}(0,0)+g_{x y}(0,0)+a_{x}(0,0) f_{x}(0,0)+a_{y}(0,0) f_{y}(0,0) \\
\phi_{y}(0,0) & =f_{x y}(0,0)+g_{y y}(0,0)+a_{x}(0,0) f_{y}(0,0)+a_{y}(0,0) f_{y}(0,0)
\end{aligned}
$$

Kemudian dipilih $\phi_{x}(0,0)=\phi_{y}(0,0)=0$ sehingga didapat

$$
\begin{aligned}
& a_{x}(0,0)=\frac{\left(f_{x x}(0,0)+g_{x y}(0,0)\right) g_{y}(0,0)-\left(f_{x y}(0,0)+g_{y y}(0,0)\right) g_{x}(0,0)}{f_{y}(0,0) g_{x}(0,0)-f_{x}(0,0) g_{y}(0,0)} \\
& a_{y}(0,0)=\frac{\left(f_{x y}(0,0)+g_{y y}(0,0)\right) f_{x}(0,0)-\left(f_{x x}(0,0)+g_{x y}(0,0)\right) f_{x}(0,0)}{f_{y}(0,0) g_{x}(0,0)-f_{x}(0,0) g_{y}(0,0)}
\end{aligned}
$$

Karena $\phi_{x}(0,0)=\phi_{y}(0,0)=0$, persamaan (9) menjadi

$$
\phi(x, y)=\phi(0,0)+\frac{1}{2}\left(\phi_{x x}(0,0) x^{2}+2 \phi_{x y}(0,0) x y+\phi_{y y}(0,0) y^{2}\right)+\cdots
$$

Kemudian dianalisa sifat definit positif dari $\phi(x, y)$ dan selanjutnya dari Persamaan 9 dicari turunan kedua didapat :

$$
\begin{aligned}
& \phi_{x x}(0,0)=Q^{x x}+2 f_{x}(0,0) a_{x x}(0,0)+2 g_{x}(0,0) a_{x y}(0,0) \\
& \phi_{x y}(0,0)=Q^{x y}+f_{y}(0,0) a_{x x}(0,0)+g_{x}(0,0) a_{y y}(0,0) \\
& \phi_{y y}(0,0)=Q^{y y}+2 f_{y}(0,0) a_{x y}(0,0)+2 g_{y}(0,0) a_{y y}(0,0)
\end{aligned}
$$

Tanda definit positif dapat ditentukan dari turunan kedua $\phi(x, y)$ terhadap $x$, yaitu

$$
\phi_{x x}(0,0)=\frac{1}{2}\left(Q^{x x}-Q^{y y} \frac{g_{x}(0,0)}{f_{y}(0,0)}\right)-Q^{x y} \frac{f_{x}(0,0)}{f_{y}(0,0)}
$$

Dengan menggunakan (14) diperoleh jenis bifurkasi Hopf. Jika $\phi_{x x}(0,0)$ positif diperoleh bifurkasi Hopf subkritikal dan jika $\phi_{x x}(0,0)$ negatif maka diperoleh bifurkasi Hopf superkritikal.

\subsubsection{Penerapan pada Masalah Predator Prey}

Diberikan suatu sistem predator prey

$$
\dot{x}=x\left(1-x-\frac{2 y}{1+2 x}\right) \quad \dot{y}=y\left(\frac{2 x}{1+2 x}-\mu\right)
$$


dimana

$x=$ populasi dari prey

$y=$ predator

$\mu=$ parameter (diasumsikan positif)

Titik setimbang center saat $\mu=\frac{1}{3}$ adalah $\left(\frac{1}{4}, \frac{9}{16}\right)$. Dengan kriteria divergensi dibentuk sistem baru. Misal $\phi(x, y)$ adalah divergensi dari $(a f, a g)$.

Dengan kriteria divergensi diperoleh nilai koefisien fungsi kuadrat

$$
a(x, y)=1+2,7 x-1,8 x^{2}+2,7 x y+1,2 y^{2}
$$

Diperoleh sistem yang baru

$$
\begin{aligned}
z(x, y) & =a(x, y) \cdot f(x, y) \\
& =\left(1+2,7 x-1,8 x^{2}+2,7 x y+1,2 y^{2}\right) \cdot\left(x-x^{2}-\frac{2 x y}{1+2 x}\right) \\
w(x, y) & =a(x, y) \cdot g(x, y) \\
& =\left(1+2,7 x-1,8 x^{2}+2,7 x y+1,2 y^{2}\right) \cdot\left(\frac{2 x y}{1+2 x}-y \mu\right)
\end{aligned}
$$

Untuk membuktikan apakah sistem yang baru juga center maka dilakukan pelinieran dan diperoleh matriks Jacobi di titik $\left(\frac{1}{4}, \frac{9}{16}\right)$ yaitu

$$
J=\left(\begin{array}{cc}
z_{x}(x, y) & z_{y}(x, y) \\
w_{x}(x, y) & w_{y}(x, y)
\end{array}\right)_{\left(\frac{1}{4}, \frac{9}{16}\right)}=\left(\begin{array}{cc}
0 & -0,774 \\
1,1609 & 0
\end{array}\right)
$$

Kemudian akan dicari nilai eigen dari matriks Jacobinya. Dari $|\lambda I-J|=0$ diperoleh

$$
\lambda^{2}+(0,774)(1,1609)=0
$$

sehingga akar-akar karakteristik adalah

$$
\lambda_{1,2}= \pm 0,95 i
$$

Didapat nilai eigen dengan bagian real sama dengan nol dan merupakan imajiner murni maka system yang baru terbukti berupa center.

Untuk menentukan jenis bifurkasi Hopf maka perlu diketahui nilai $\phi_{x x}(\bar{x}, \bar{y})$ berdasarkan Persamaan 1, didapat

$$
a_{x}\left(\frac{1}{2}, \frac{9}{16}\right)=2,6 \quad \text { dan } \quad a_{y}\left(\frac{1}{2}, \frac{9}{16}\right)=0
$$

Berdasarkan Persamaan 14 dihitung $\phi_{x x}(\bar{x}, \bar{y})$ dengan

$$
Q^{x x}=-8,4 \quad Q^{y y}=-3,04 \quad Q^{x y}=-2,109
$$


sehingga

$$
\begin{aligned}
\phi_{x x}(\bar{x}, \bar{y}) & =\frac{1}{2}\left(Q^{x x}-Q^{y y} \frac{g_{x}(\bar{x}, \bar{y})}{f_{y}(\bar{x}, \bar{y})}\right)-Q^{x y} \frac{f_{x}(\bar{x}, \bar{y})}{f_{y}(\bar{x}, \bar{y})} \\
& =\frac{1}{2}(-8.8+4.6)=-1,9
\end{aligned}
$$

Karena $\phi_{x x}\left(\frac{1}{2}, \frac{9}{16}\right)=-1,9<0$ artinya divergensi pada ruang vektor dari sistem (1) negatif, artinya titik setimbang merupakan spiral yang stabil, sehingga dengan adanya center di sekitar titik $(0,0)$ berakibat terjadinya limit cycle yang stabil maka disebut bifurkasi Hopf superkritikal.

\section{Analisa}

Untuk menentukan jenis bifurkasi Hopf dengan dua metode yaitu penyelesaian bentuk normal dan metode kriteria divergensi diperoleh hasil analisis bahwa pada sistem predator prey (1) merupakan bifurkasi Hopf superkritikal. Terlihat bahwa langkah penyelesaian dengan metode kriteria divergensi lebih sederhana jika dibandingkan dengan penyelesaian bentuk normal karena pada tidak memerlukan langkah dalam mencari vector eigen, translasi titik setimbang ke $(0,0)$ serta tidak melalukan transformasi bentuk linier dari medan vektor ke bentuk kanonik

\subsection{Analisa Potret Fase pada Sistem Predator Prey}

\section{a. Potret fase pada nilai $\mu=0.33$}

Potret fase merupakan suatu pusat (center) yang stabil netral, maka titik setimbang punya orbit periodik. Karena stabil netral maka dapat berubah jadi stabil, stabil asimtotis, atau tidak stabil. Adanya gangguan (parameter) dapat mempengaruhi stabilitas titik tetap. Dengan diberikan gangguan pada sistem, menyebabkan titik setimbang dapat berubah menjadi suatu focus yang kestabilannya bergantung $\mu$.

Kemudian akan dianalisa bagaimana potret fase saat $\mu<0,33$ dan saat $\mu>$ 0,33 .

b. Pada saat $\mu<0,33$

Misal $\mu<0,2$, maka akar-akar karakteristik

$$
\begin{aligned}
\lambda_{1,2} & =\frac{\left(-\frac{\mu(1-3 \mu)}{2(1-\mu)}\right) \pm \sqrt{\left(\frac{\mu(1-3 \mu)}{2(1-\mu)}\right)^{2}-4\left(\frac{2-3 \mu}{2(1-\mu)^{2}}\right) \mu}}{2} \\
& =\frac{1}{2}\lfloor-0,05 \pm \sqrt{0,8725 i}\rfloor \\
& =-0,025 \pm 0,467 i
\end{aligned}
$$




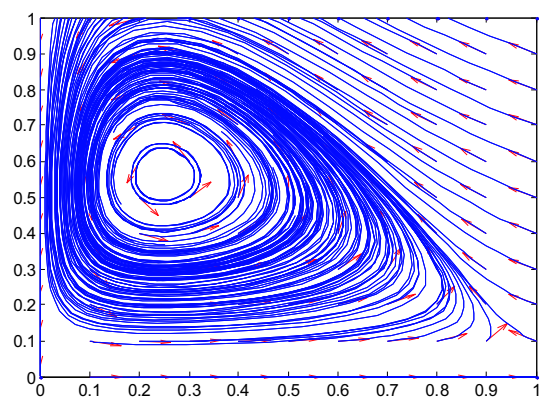

Gambar 1: Potret Fase saat $\mu=0,33$

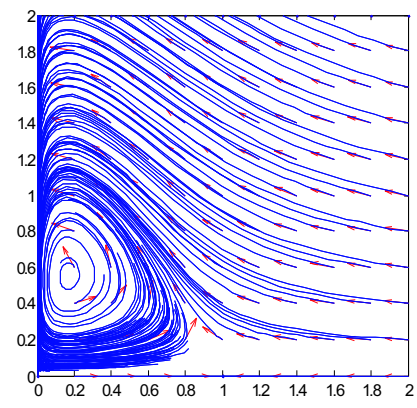

Gambar 2: Potret Fase saat $\mu=0,2$

Terlihat bahwa nilai eigen adalah imajiner dengan bagian real negatif, maka pada saat $\mu=0,2$ titik setimbang merupakan focus yang stabil. Dengan demikian saat nilai $\mu<0,33$ terlihat bahwa titik setimbang berubah menjadi focus yang stabil dengan adanya center sehingga terdapat limit cycle yang stabil. Potret fase saat nilai $\mu=0,2$ diberikan seperti Gambar 2 .

c. Pada saat $\mu>0.33$

Kemudian $\mu$ diperbesar dari $\mu=0,33$ menjadi $\mu=0,4$. Misal $\mu=0,4$, maka akar-akar karakteristik

$$
\begin{aligned}
\lambda_{1,2} & =\frac{\left(-\frac{\mu(1-3 \mu)}{2(1-\mu)}\right) \pm \sqrt{\left(\frac{\mu(1-3 \mu)}{2(1-\mu)}\right)^{2}-4\left(\frac{2-3 \mu}{2(1-\mu)^{2}}\right) \mu}}{2} \\
& =\frac{1}{2}\lfloor 0,066 \pm \sqrt{1,774} i\rfloor \\
& =0,033 \pm 0,667 i
\end{aligned}
$$

Terlihat bahwa nilai eigen adalah imajiner dengan bagian real positif, maka pada saat $\mu=0,4$ titik setimbang merupakan focus yang tidak stabil. Dengan demikian saat nilai $\mu>0,33$ terlihat bahwa titik setimbang berubah menjadi focus yang tidak stabil dengan adanya center sehingga terdapat limit cycle yang tidak stabil.

\section{Kesimpulan}

Kesimpulan yang dapat diberikan adalah untuk menentukan jenis bifurkasi Hopf dengan dua metode yaitu penyelesaian bentuk normal dan metode kriteria divergensi diperoleh hasil bahwa pada sistem predator prey (1) merupakan bifurkasi 
Hopf superkritikal. Terlihat bahwa langkah penyelesaian dengan metode kriteria divergensi lebih sederhana jika dibandingkan dengan penyelesaian bentuk normal karena pada tidak memerlukan langkah dalam mencari vector eigen, translasi titik setimbang ke $(0,0)$ serta tidak melalukan transformasi bentuk linier dari medan vector ke bentuk kanonik. Dengan demikian dapat disimpulkan bahwa langkah penyelesaian dengan metode kriteria divergensi lebih sederhana jika dibandingkan dengan penyelesaian bentuk normal. Sehingga metode kriteria divergensi dapat dijadikan sebagai alternatif penyelesaian yang lebih mudah dan lebih singkat.

\section{Pustaka}

[1] Hale,J and Kocak, Dynamics and Bifurcations, Springer-Verlag, New York, 1991.

[2] Hofbauer. J and So. J.W.H,(1990), Multiple Limit Cycle for Predator-prey Models, Math. Biosci.

[3] Hoppensteadt .F and Waltman. P, (2002), Did Something Change?Thresholds in Population Models, Berlin, pp 341-374.

[4] Pilyugin, S.S and Waltman. P., (2003), Multiple Limit Cycles in Chemostat with Variable Yield, Math. Biosci, 182 pp 151-166.

[5] Pilyugin.S.S and Waltman. P., (2003), Divergence Criterion for Generic Planar System, SIAM J Appl. Math., vol 64 no 1, pp 81-93.

[6] Robinson, Clark,R.. P., (1997), An Introductionto Dinamical System Continous and Discrete Prentice Hall, New Jersey.

[7] Wiggins,S., (1990), Introduction to Applied Nonlinier Dynamical Systems and Chaos, Springer-Verlag, New York. 